\title{
COMPOSIÇÕES DO CORPO PARA CONSUMOS: UMA REFLEXÃO INTERDISCIPLINAR SOBRE SUBJETIVIDADE
}

\author{
COMPOSICIONES DEL CUERPO PARA CONSUMOS: UNA REFLEXIÓN \\ INTERDISCIPLINARIA SOBRE LA SUBJETIVIDAD \\ BODY'S COMPOSITIONS FOR CONSUMPTION: AN INTERDISCIPLINARY \\ REFLECTION ABOUT SUBJECTIVITY
}

http://dx.doi.org/10.1590/1807-03102015v27n2p246

Mário Pereira Borba e Inês Hennigen

Universidade Federal do Rio Grande do Sul, Porto Alegre/RS, Brasil

\section{RESUMO}

Neste artigo discutimos a importância da ambiência midiática e publicitária para a composição de sentidos em torno do corpo. Tal atividade simbólica evidencia-se enquanto um lugar privilegiado de construção do sujeito moderno, ao dispor seus traços significantes relacionados à corporeidade, em convidativas negociações dos limites na constituição, reativa, dos sentidos relacionados ao corpo: disposições que orientam os processos de subjetivação, em ciclos de caracterizações provisórias. Articulamos questões em torno da relação corpo/ discurso/subjetividade, tramando um diálogo entre pensadores oriundos de diferentes campos, partindo deste lugar ocupado pelo corpo como convocado para consumos, nas emanações sutis do discurso publicitário. Nesse sentido, refletimos sobre a dinâmica dos jogos de verdade, das técnicas de si contemporâneas, enquanto propõem a experiência de um cuidado e de uma liberdade de escolhas relacionados à segurança ontológica, muitas vezes em vista da coerência e aceitabilidade social.

Palavras-chave: corpo; consumo; subjetividade; publicidade.

\section{RESUMEN}

En este articulo hablamos de la importancia de los medios y el ambiente de la publicidad para la composición de los sentidos del cuerpo. Dicha actividad simbólica aparece como un lugar privilegiado de la construcción del sujeto moderno, a tener sus rasgos significativos relacionados con la corporeidad, al invitar las negociaciones en los limites de la constitución, relativa, de los sentidos relacionados al cuerpo: las disposiciones aplicables para dar forma a los procesos de subjetividad en los ciclos de caracterizaciones provisionales. Cuestiones articuladas alrededor de la relación cuerpo/ discurso/subjetividad, trazando un diálogo entre pensadores de diferentes ámbitos, a partir de este lugar ocupado por el cuerpo como invitado para el consumo, en las emanaciones sutiles del discurso publicitario. En este sentido reflexionamos sobre la dinamica del juego de la verdad, y las tecnicas contemporaneas como propone la experiencia de la atención y la libertad de opciones relacionadas con la seguridad ontológica a menudo en vista de la coherencia y la aceptación social.

Palabras clave: cuerpo; consumo; subjetividade; publicidad.

\begin{abstract}
This paper discusses the importance of media context and advertising for composition of meanings around the body. This symbolic activity shows up as a privileged place of modern subject construction by evidencing significant traits related to corporeality and limits in the reactive formation of meanings related to body: dispositions that guide processes of subjectivity in cycles of provisional characterizations. This paper articulates issues around body/discourse/subjectivity relation. We build a dialogue between thinkers of different fields to analyze the body's role when it is invited to consume in subtle emanations of advertising discourse. In that sense, this paper reflects on the dynamics of truth games and contemporary techniques of self awareness, while proposing an experience of care and freedom of choice related to ontological security, often in view of coherence and social acceptability.
\end{abstract}

Keywords: body; consumption; subjectivity; advertising. 


\section{Introdução}

Este artigo aborda aspectos da construção de sentidos em torno do corpo a partir da lógica do consumo. Uma revisão bibliográfica de autores de diferentes campos - situamos suas contribuições entre filosofia, sociologia, comunicação, antropologia e psicologia social - nos permite perspectivar a percepção dos contextos socioculturais agindo sobre os corpos, que, complacentes ou indisciplinados, se constituem como arena de conflitos simbólicos que participam da constituição subjetiva dos sujeitos. Ao desenvolver uma discussão teórica interdisciplinar, tecida transversalmente ao longo do escrito, pretendemos evidenciar a relação corpo/discurso/ subjetividade no âmbito do consumo e problematizar os atravessamentos nas formas de se relacionar com o corpo no contemporâneo.

Consideramos assaz pertinente problematizar a lógica e o lugar ocupado pelas mediações midiáticas nos processos de subjetivação, visto as constantes convocações que se processam atualmente em estímulos para a manutenção do consumo e a ampliação do mercado. Particularmente, onde tais estímulos direcionam padrões em torno da corporeidade, com elementos que compõem jogos de verdade, tendo em vista certa crise da subjetividade - capturada e investida pelas dinâmicas mercadológicas. Quer parecer que a publicidade adquire força na atualização das suas representações e no poder persuasivo dos seus conteúdos (simbólicos), acelerando a obsolescência dos processos de identificação, em sintonia com o imperativo de velocidade cultuado no desenvolvimento tecnológico.

Em face disso, procuramos evidenciar o engajamento do corpo nesses processos, enquanto um lugar privilegiado de enlace e desenlace, de agenciamentos. Através da problematização do que está posto no âmbito da publicidade, buscamos abordar o corpo capturado, no consumo, entre espaço e tempo. Neste sentido, discutimos aspectos da relação do desejo e das experiências emocionais com a cultura colocados nessa convocação. Sob a perspectiva foucaultiana e com uma inspiração antropológica, refletimos acerca da atividade simbólica em torno das emoções (cristalizadas na publicidade), que aparece como um lócus privilegiado de produção do sujeito moderno. Por fim, mas não por último, entendemos que, no universo retórico de uma cultura de consumo sem limites, consumo do excesso, o corpo consome e é consumido, principalmente a partir de sentidos em torno dele mesmo. O corpo como espaço e o desejo como parceiro, motor do consumo, materialização da relação sujeito-sociedade, onde se corroboram conflitos e excessos do nosso tempo, como a manutenção/ exploração de uma ideia de individualidade, a ser consumida. Assim sendo, não deixamos de pensar a relação estrutural da publicidade, do consumo, com uma concepção de (e uma expressão do) indivíduo própria do capitalismo liberal.

\section{Distâncias e mediações}

Inovações tecnológicas ligadas à difusão das formas simbólicas estão, desde as primeiras técnicas de impressão, relacionadas ao desenvolvimento de indústrias como a (que se convencionou chamar de) cultural, da informação e da mídia. Estas, ao longo dos anos, amadureceram processos de mediação inerentes à venda dos produtos simbólicos, constituindo-se em centros e redes de poder simbólico. Essa maturação, desde o século XIX, esboça uma configuração extensiva que, sempre potencializada pelo uso de novas ferramentas tecnológicas, sobretudo as eletronicamente mediadas - a que Thompson (2008) faz menção quando trata da evolução de tais redes de poder simbólico -, constituiu uma verdadeira revolução instrumental, na medida em que permitiu tamanha intensificação dos fluxos comunicacionais, que de certa forma "reduziram as distâncias", tornando-se a base da dita era da informação e da globalização. Muitos autores falam, então, de uma nova ordem de mediações, característica das sociedades complexas e orientadas a partir desses dispositivos tecnológicos geradores de realidade, a que se referem como "midiatização". Ambiência que aqui referimos como ethos midiatizado, inspirados em expressão/pensamento de Sodré (2006) acerca da potência de revestimento e regulação da consciência, condutas e costumes sociais a partir das matrizes midiáticas, incrementada pelo acoplamento entre a economia mercantil e a economia do desejo.

Interessa assinalar tal fenômeno dessa perspectiva porque, a partir dela, podemos observar que hoje o mosaico de mensagens que, intensificadas pela disposição midiática, atravessa as sociedades interfere fortemente nas condições nas quais a realidade se apresenta, propondo relações (consigo) e novas formas de habitar um mundo criado pelas novas formas de deslocamento (de corpos e informações), por exemplo, e nelas uma liberdade e/ou um imperativo de velocidade. Importa destacar que o carro-chefe destas transformações, como aponta uma tendência indicada por Thompson (2008) no desenvolvimento da mídia (a partir de interesses comerciais de larga escala), é a manutenção do consumo (do mercado) em suas diversas manifestações. Parece que hoje, ainda 
mais do que em um passado próximo, os apelos para consumos simbólicos incrementam identificações fugazes, costurando através delas pertencimentos estreitos, amplos ou sutis. E que na significação fruto dos estímulos (consumidos), e, a partir disso, na negociação de culturas, está esboçada a singular construção discursiva em torno do que poderíamos ser em meio à miscelânea de pertencimentos possíveis, manifestados em consumos.

Segundo Giddens (2002), as convenções cotidianas mantêm sob controle nosso "estar no mundo", protegendo-nos de uma crise iminente, do caos que espreita de um "outro lado" das orientações da vida prática, ansiedades que atingiriam a raiz da nossa sensação da realidade partilhada das pessoas e das coisas, nossa estabilidade diante de questões existenciais e do que se possa chamar de autoidentidade. Para o autor, a "atitude natural põe entre parênteses perguntas sobre nós mesmos, sobre os outros e sobre o mundo dos objetos, que devem ser dadas como respondidas para que se possa enfrentar a atividade cotidiana" (2002, p. 40). Os sentidos difundidos e construídos socialmente na cultura oferecem modos de orientação a partir da provisão de interpretações simbólicas de questões existenciais. Partimos do entendimento de cultura como proposto por Geertz (1989), em um sentido essencialmente semiótico, relacionado a teias simbólicas, de significados (re)tecidos socialmente - compartilhando da perspectiva de Max Weber, ao considerar o homem como um animal amarrado a tais teias que ele mesmo teceu. Destacamos aqui o lugar da publicidade nessa tessitura de sentidos, onde a pluralidade, a diversidade, e, muitas vezes, a ambiguidade, são marcas de suas composições e assédios. Resta assim um paradoxo no processo de apropriação que seria a própria anestesia das angústias existenciais, do "estar" social, porque as ansiedades, seguindo o raciocínio de Giddens (2002), se nos espreitam do outro lado das orientações práticas da vida social, também são o fermento de muitos dos apelos publicitários - talvez principalmente dos que se referem a expressões do corpo.

\section{O corpo: tempo, imagem e simulações}

O corpo comparece como meio fundamental por onde se manifestam os assédios referidos acima, em termos de ser seguidamente convocado e mobilizado na relação com os outros, situando, como superfície, relações com as convenções e decisões relativas ao que seria próprio de algum padrão identitário. $\mathrm{O}$ caminho pontilhado nas formas do consumo, entre padronizações e singularidades, é imanentemente tortuoso e não dura mais do que um desejo, que é investido, logo em seguida, de outro; imperativos, ansiedades: o próprio corpo. A convocação social do corpo na publicidade evidencia sua importância imagética, um cartão de visitas; a conformidade social embaralhada com os padrões e tendências de consumo incita um corpo que anseia entre a autoconfiança e a vergonha. Uma vergonha desviada, seguindo o pensamento de Giddens (2002), correlata a ansiedades inconscientemente experimentadas sobre inadequações do eu: "A vergonha desviada se liga diretamente a sentimentos de insegurança ontológica ... consiste em medos reprimidos de que a narrativa da auto-identidade possa não suportar pressões envolventes sobre sua coerência ou aceitabilidade social" (p. 66). No entanto, estímulos diversos envolvem adendos possíveis cada qual com a carga simbólica de sua marca - nos produtos: regimes possíveis. E não há uma autoridade máxima para onde direcionar a segurança ontológica, muitos disputam.

Para além dos adendos a serem consumidos, um corpo controlado, leia-se atento às diretrizes da boa saúde, com todas as discrepâncias e contradições que podem circular em prescrições relacionadas a isso, um corpo empoderado na ascese de um regime qualquer é o emblema de uma imagem segura frente aos diferentes ambientes sociais. Mas os regimes são muitos, e os maneirismos próprios e as validações efêmeras pululam com acessos aparentemente facilitados por consumos específicos, por isso o controle sobre tal imagem é igualmente um artigo para o consumo. Nas palavras de Giddens (2002, p. 160 ), "o consumo interpela as qualidades alienadas da vida social moderna e se apresenta como a solução: promete as coisas mesmas que o narcisista deseja - charme, beleza e popularidade - através do consumo dos tipos certos de bens e serviços". O corpo, assim, consome e é consumido. Pode-se pensar que essa relação individual com o corpo é investida de estímulos no relacionamento com as formas simbólicas que circulam no material publicitário, seja na identificação de um ideal de si mesmo inalcançável (porque interessa mais o desejo do que as satisfações, efêmeras), seja no acoplamento de indumentárias (vendidas) que garantam extensões bem-vistas do corpo. Imagens que compõem nossa relação com o corpo, a serem vividas como moradas.

Esta imagem que flui sobre o corpo inspira uma temporalidade própria, outra, muitas vezes uma negação do tempo que age sobre o corpo, marcas cravadas pelo tempo na identidade. Debord (1997) fala de um tempo-mercadoria, da acumulação infinita de intervalos equivalentes, inversões no passar de um 
tempo dominado socialmente, mas um tempo que pode tudo, restando ao homem, desvalorizado, apelar para o tempo consumível, qual seja um tempo pseudocíclico, que é "o disfarce consumível do tempo mercadoria da produção", mas "como ele é o subproduto desse tempo destinado ao atraso da vida cotidiana concreta - e à manutenção desse atraso -, deve estar carregado de pseudovalorizações e aparecer numa sequência de momentos falsamente individualizados" (p. 104).

Muitos falam de uma temporalidade própria da cultura contemporânea, vetorizada pela ambiência tecnológica dos meios de comunicação. Como motor do consumo, a publicidade adquire força na atualização das suas representações e no poder persuasivo dos seus conteúdos (simbólicos); assim, acelera a obsolescência dos processos de identificação, ecoando e realimentando a velocidade imprimida no desenvolver tecnológico. Sodré (2006), em consonância com Martin Barbero, retifica na contemporaneidade o acréscimo da mídia como "concretização tecnológica de uma moralidade vetorizada pelo mercado" (p. 190), e, ao destacar o aspecto profético do discurso midiático - que "procura deixar claro que o futuro já chegou e o reino dos céus está ao alcance de qualquer consumidor" - enfatiza, "consumo e moralidade passam a equivaler-se" (p. 50). É da dinâmica do capitalismo a criação de consumidores que "têm necessidades diferenciadas (e cultivadas); a secularização tem o efeito de estreitar o significado moral até o imediato da sensação e da percepção" (Giddens, 2002, p. 158), razões apontadas como difusoras do narcisismo.

Alguns pensadores, como Debord (1997), questionam a evolução da existência guiada pelas imagens e/de consumo. Para esse autor, a sociedade espetacular "não é um conjunto de imagens, mas uma relação social entre pessoas, mediada por imagens" ( $p$. 14). Sob essa ótica, a partir de uma expansão econômica que ergue mercadorias e se apodera de imagens e imaginários, é apresentada uma vasta realidade a ser consumida, sob os dogmas do espetáculo, pelos sujeitos-consumidores. Em tais processos, a liberdade de escolha sem limite, promovida com a multiplicação das ofertas, por vezes surge como uma afirmação abstrata da individualidade (que os frankfurtianos denunciavam ter sido solapada pela indústria cultural). Essa individualidade (em valores que ganham concretude na materialização histórica, também através do consumo), afirmada para além das típicas diferenciações sociais, delineia um terreno ironicamente comum por onde circulam as imagens e os discursos a serem comprados e difundidos pelos atores, vestidos a caráter, nos tantos "monólogos" encenados no consumo. Então, o mundo-imagem passeia pelo ser, arranca-lhe sensações, solicita-o para que se entregue. E ele cede. Entrega seu olho ao espetáculo e, o que é mais significativo, reduz-se ao próprio olho. Ele, o outro e o mundo são o que é visto e vivido na imagem. (Tonin, 2007, p. 48)

Neste sentido, cabe mencionar as ponderações de Calvino (2008), que se preocupa com certo automatismo generalizado, que tende a nivelar nossa expressão em fórmulas genéricas, anônimas, abstratas, a diluir significados, extinguir qualquer centelha que crepite no encontro das expressões, das palavras, com as novas circunstâncias. Como literato, ele indica, por meio da literatura, anticorpos para a "salvação". E, em sua crítica, aponta a mesma pestilência da linguagem escrita na chuva ininterrupta de imagens a que estamos expostos.

Os media todo-poderosos não fazem outra coisa senão transformar o mundo em imagens, multiplicando-o numa fantasmagoria de jogos de espelhos - imagens que em grande parte são destituídas da necessidade interna que deveria caracterizar toda imagem, como forma e como significado, como força de impor-se à atenção, como riqueza de significados possíveis. Grande parte dessa nuvem de imagens se dissolve imediatamente como os sonhos que não deixam traços na memória; o que não se dissolve é uma sensação de estranheza e mal-estar. (Calvino, 2008, p. 73)

As aspirações seguem um trilho individual, o próprio olho, o próprio corpo; “daí que todos nós, nas condições sociais modernas, vivemos como que cercados de espelhos; neles procuramos a aparência de um eu socialmente valorizado, imaculado" (Giddens, 2002, p. 160). O cartógrafo-personagem de Rolnik (2011) descobre junto com um personagem de Hitchcock a experiência crucial de sua época: "A simulação é a própria condição da vida" (p. 100). E, por mais que uma simulação qualquer seja reiteradamente explicitada e passe a sacudir as seguranças (psicológica e ontológica) do sujeito que se depara com a vertigem de um deslocamento nas suas tramas - de sentido, como diria Geertz (1989) -, tal simulação nunca é abolida. No entanto, mesmo que se saiba disso, "o que move a vida", diz Rolnik (2001, p. 100), "é exatamente a busca infrutífera e sempre recomeçada dessa abolição"; nessa busca, segunda a autora, é que se tecem enredos, figuras e sonhos.

As representações (apresentações ou significações de aspirações, ansiedades, medos, etc.) que circulam nos materiais publicitários orientam valores $^{1}$, garimpam e instituem tendências entre as formas de se relacionar socialmente. A partir disso, configura-se uma articulação possível entre o 
desenvolvimento das tecnologias de comunicação e informação e suas interferências na cultura, costumes e formas de compreensão e interação com o mundo, visto que, enquanto promovem novos espaços de mediação e interação social, abrem caminho para novas formas de relacionamentos dos sujeitos com as formas simbólicas consumidas e, consequentemente, da assimilação ou projeção dos seus discursos. De acordo com Sodré (2006, p. 50), "a midiatização da sociedade oferece a perspectiva de um eticismo vicário ou paralelo, atravessado por injunções da ordem $<$ ter de $>$ e $<$ dever $>$ e suscetível de configurar uma circularidade de natureza moral, fundamentada pela tecnologia e pelo mercado".

Pontuamos, a partir disso, no que tange aos aspectos narcísicos da relação contemporânea com o corpo, que, antes de ser uma alienação com relação ao social - algo da ordem de uma retirada defensiva do mundo exterior, uma vez que a midiatização da sociedade comporia essa realidade exterior -, essa interação imagética, ao contrário, constitui um envolvimento com o mundo tal qual ele se apresenta. Ainda, que tais movimentos de obsolescência, simulação, enlace e desenlace, articulação e abolição favorecem a desorientação, certo desamparo. E, quanto mais desamparo, mais inclinados se veem os sujeitos às distribuições de sentido e valores que são vetorizadas no mercado.

O corpo é, assim, retomado na modernidade sob incitações diversas. Corpo que já foi o ponto de partida de desejos (perversos, proibidos) a serem contidos, sob uma moral de orientação majoritariamente religiosa, prisão da alma. Hoje, enquanto comparece atravessado por injunções em nível social, ao mesmo tempo figura como instância por excelência dos processos reflexivos de interação individual com o que Giddens (2002) chamaria de "sistemas abstratos" que o invadem. Ou seja, no nível da política-vida, de enfrentamento pessoal, reflexivo, da realidade dos sistemas sociais, globais e locais, a relação com o corpo expressa emancipações de ordem geral, que reorientam as implicações pessoais e políticas da vida. Como indica Foucault (2004) quando se refere ao cuidado de si, a atividade do sujeito se constituindo a partir de práticas de liberdade, a relação consigo para além das linhas de poder, nos dispositivos, que incidem sobre os corpos - é um ponto de resistência. Muitos autores (Ortega, 2001; Silva, 2005) concordam na leitura da retomada histórica que o filósofo faz do cuidado de si na Grécia antiga como uma (possível) resposta às práticas subjetivantes modernas. Assim, ponto de resistência porque o que está em questão não é da ordem da natureza do sujeito, não o que seriam formulações para o sujeito a partir somente do que está colocado para ele, mas o que possibilita a constituição de modos de ser a partir da relação consigo. São as formas decorrentes dos processos de subjetivação que, sob esse viés, evidenciam a relação do sujeito com os jogos de verdade.

Se, em Vigiar e punir, Michel Foucault salienta o poder exercido sobre o corpo, que fabrica indivíduos individualizando-os pela disciplina, aplainando tempo e espaço, que opera pelos critérios da norma, entre visibilidades e segmentaridades, em História da sexualidade I - a vontade de saber, ele descreve o dispositivo de sexualidade como "um poder que atua novamente sobre o corpo e o semeia de realidade, doando-lhe uma identidade que também constitui uma forma de assujeitamento: ao mesmo tempo sujeição e subjetivação" (Ortega, 2001, p. 160). Tomando o conceito de biopoder apresentado por Foucault (2010a), podemos pensar a relação, ou os processos reflexivos, na construção de traços significantes, marcados por uma individualização característica das sociedades disciplinares descritas pelo autor, mesmo que em espaços cada vez mais abertos, característicos da nossa sociedade atual - ou sociedade de controle, transição apontada por Foucault e trabalhada por Deleuze (2005).

Pensar as novas formas de intervenção que agem sobre os corpos sob inspiração sócio-histórica, à luz destes referenciais, é tomá-las nos rastros da emanação sutil das normalizações do saber, na relação com os jogos de verdade, com as técnicas de si. Não é algo que incide de cima para baixo, como marca de um poder centralizado, tampouco com o rigor que a disciplina leva a supor a docilidade dos corpos, mas efeitos de inúmeras tecnologias que se recriam, embatem, sobrepõem: tecnologias do saber, modos de viver, discursos. Então, produtos, diagnósticos, estéticas, entre as inúmeras verdades disponíveis sobre o corpo, propõem que cada um atente para as demandas de seu corpo, e se responsabilize por elas, a partir do que está colocado como necessidades no mercado global; ainda, que também experimente nisso um cuidado de si voltado à ampliação do prazer, que está, muitas vezes, relacionado à segurança ontológica em vista da coerência e aceitabilidade social. A partir disso, convergem demandas por vezes cruzadas e contraditórias do consumo, nas fronteiras entre saúde, bem-estar, prazer e beleza, por exemplo.

É uma característica da sociedade de controle repassar ao indivíduo a idéia de que ele é responsável por sua vida e por seu nível de saúde, cabendo-lhe postergar a finitude do corpo e os efeitos do tempo. Contudo, se o sujeito pode agora potencializar o seu 
prazer - amparado por tecnologias que lhe permitem conhecer e positivar os riscos -, ele precisa, mais do que nunca, administrar essa liberdade. (Lucas \& Hoff, 2006, p. 91)

O indivíduo livre para intervir no próprio corpo é "municiado" com produtos cada vez mais sofisticados para explorar seus limites. $\mathrm{O}$ aspecto reflexivo desse cuidado como reinvenção do corpo acena para o papel decisivo dos modelos disponíveis na cultura midiática. Estes, mais do que corpos saudáveis, são corpos desenhados, quiçá impossíveis; híbridos. O ponto de chegada de um projeto de "remodelagem". As características de tais modelos denotam o hibridismo entre os cuidados com o corpo e o discurso da saúde, como diria Bruno (1994, p. 94): “A diet'ética se afirma como processo identitário". Essa dietética seria uma condição da ética a partir do que está posto, dessas técnicas de si contemporâneas, uma administração estética, pelo consumo, das virtualidades anunciadas pelo discurso midiático.

\section{Subjetividade, relações e dispersões de sentidos}

Foucault identifica que os acontecimentos discursivos dispersam o sujeito "em uma pluralidade de posições e funções possíveis" (1996, p. 58). Diz isso enquanto questiona sobre a relação do sujeito com a verdade, sobre os esfumaçamentos possíveis entre saber e poder nessa relação. As relações de sentido que orientam a relação com o outro e consigo são perpassadas por um modo de ver; desse modo, Foucault (2010a, 2010b) desvela a afinidade intrínseca de um(a microfisíca do) poder "silencioso" sobre tais práticas. Um poder positivo, completamente amarrado, sustentado, interpenetrado por infindáveis saberes difundidos socialmente. Um caminho para refletir sobre as neutralidades, os fatos científicos e, principalmente, sobre o plano estratégico dos jogos de verdades contemporâneos.

Retomando a questão da manutenção do consumo, com base na perspectiva foucaultiana, podemos pensar, no eixo do biopoder, os jogos de verdade difundidos na publicidade agindo como mecanismos estratégicos de um poder em via de promover uma disciplina do corpo e da vida orientada para o mercado da superprodução do capitalismo atual. Não se trata daquele poder disciplinar da sociedade industrial, que visava amansar os corpos para a ampliação da produtividade, tendo o trabalho como ponto de contato, mas de um poder mais difuso, incidindo sobre os desejos, permitidos, incitados e amplificados pelas promessas de consumo objetivando a maximização do prazer, tendo o mercado como ponto de contato entre momentos, ambientes e pessoas. Tal evolução das estratégicas do poder pode ser posta em paralelo com o contexto de desenvolvimento do capitalismo. No capitalismo inicial reinava uma lógica de maximização, de acumulação. Todavia, como observou muito bem Campbell (2001), a lógica protestante da acumulação não dava conta da manutenção estrutural do capitalismo em ampla escala. Então, se sua própria sobrevida implica produzir cada vez mais, ampliar, maximizar, lucrar, o sistema depende da liberação do espaço, do escoamento da produção. $\mathrm{E}$, no que concerne ao ponto de contato das estratégias de poder, é possível identificar aqui uma transição do trabalho para o mercado, da maximização da produção, a do consumo. Analisando este movimento, Campbell (2001) propõe a ética romântica como um dos precursores do hedonismo que orientaria a face consumista do capitalismo atual.

Neste ponto, vale lembrar Foucault (2010b, p. 246), quando diz, "é isto, o dispositivo: estratégias de relações de força sustentando tipos de saber e sendo sustentadas por eles". E, para seguir a articulação, trazer sua frase, já famosa: "Alma, prisão do corpo" (Foucault, 2002, p. 29), que evidencia esta dimensão imaterial, elemento onde se articulam efeitos de tal poder mencionado, enfim, uma alma sócio-histórica. Nesta direção, Silveira e Furlan (2003) observam que essa alma,

como elemento prático-discursivo de desenvolvimento e produção de formas que se aglutinam e se inscrevem sobre o corpo, é o depositante histórico de verdades que visam a um acesso direto sobre os corpos. Sendo a alma o depositante de verdades e de discursos, o corpo é, por sua vez, o depositário de marcas e de sinais que nele se inscrevem e nele se cravam, de acordo com as efetividades de tais embates, que têm nesse corpo seu "campo de prova" e de constante confirmação e exercício. (p. 187)

\section{E eles propõem ainda que a}

corporeidade é o elemento de visibilidade de tais defrontamentos: seja no seu efeito acumulativo histórico (como superfície de inscrição de marcas e de sinais); seja nas suas conformações presentes, nos quais a fugacidade do momento presente manifesta o registro instantâneo destes embates; seja na antevisão prospectiva - em termos de antecipação de novas articulações futuras, propiciadoras de novas redisposições estratégicas dos corpos e das almas, efetuada pelo conjunto de tais embates, em toda a rede social; seja no sentido de afirmação da submissão a certo tipo de dominação; seja no sentido de resistência dessas forças. (p. 187) 
Então, vemos hoje uma nova forma de incidência do poder sobre a corporeidade. Muito além dos moldes disciplinares, os processos de subjetivação difundidos nos parâmetros do consumo contemporâneos se orientam sobre os corpos, atravessando-os sobre o escrutínio de sensações e desejos. Os corpos significam, na atualidade, a orientação material e simbólica nos sentidos do, para usar os termos de Giddens (2002), projeto reflexivo do eu. "Alma e corpo ... são apenas termos dessa dinâmica tensa entre formas de sentido em constante embate e formação" (Silveira \& Furlan, 2003, p. 191). Parece evidente uma maior liberdade individual se considerarmos o vasto escopo de disposições possíveis com relação ao corpo. Contudo, inspirados nos questionamentos de Bauman (2009) a respeito da elaboração do corpo como potencialidade na sociedade líquido-moderna, torna-se pertinente ponderar que talvez essa "impressão de liberdade ampliada seja apenas um polimento no que de fato é um conjunto modificado de necessidades" (p. 119).

Para acompanhar tais movimentos, cabe lançar mão do conceito de dobra (Deleuze, 2005). Os sentidos que circulam como valores estéticos são internalizados, numa regra singular que vai pautar a relação consigo, uma segmentação do movimento contínuo de desterritorialização característica da sociedade atual. Os modos de subjetivação, nesse aspecto, estão sempre ligados a uma busca de estabilização de certo tipo de relação consigo.

Tomando a dobra como operador conceitual para refletir acerca das especificidades dos processos de subjetivação descritos até aqui, pode-se pensar qualquer produção subjetiva como coextensiva à produção de um determinado tipo de configuração do campo social, ou seja, condições sociais que dão possibilidade de emergência a certos modos de subjetivação. Assim, no que concerne ao desenvolvimento do capitalismo (da produção/acumulação à superprodução/consumo/ descarte; da potencialização dos estímulos midiáticos, centrais para a vitalidade de tal circuito), percebese uma nova orientação subjetiva. Essa estaria, dentre outras incidências, como destaca Silva (2005), promovendo uma privatização dos modos de subjetivação a partir de desterritorializações de valores tradicionais, reterritorializando-os no capital - características do que Felix Guatarri, segundo a autora, chama de modos de subjetivação capitalísticos. Tratar-se-ia de uma homogeneização dos valores no equivalente geral do capital. Aqui, mais uma vez, remetemos aos modelos operatórios, ilustrados no consumo, do engendramento saber-poder, justamente por incidir sobre significações possíveis, relacionadas à corporeidade, em convidativas negociações dos limites na construção, reativa, dos sentidos relacionados ao corpo, cartografias gerais que orientam os processos de subjetivação. Neste sentido, Rolnik (2001) identifica uma anestesia geral na autonomia e na criação dos processos subjetivos na vida social.

O homem comum ... perde as rédeas dessa atividade de criação de valor e sentido para as mudanças que se operam incessantemente em sua existência e passa a orientar-se em função de cartografias gerais, estabelecidas a priori, a serem passivamente consumidas. Constitui-se a figura de indivíduo, entidade fechada em si mesma, que extrai o sentimento de si, de uma imagem vivida como essência, que se mantém idêntica a si mesma, imune à alteridade e seus efeitos de turbulência. É o princípio identitário regendo a construção da subjetividade, sob o regime exclusivo da representação. (Rolnik, 2001, p. 317)

Nessa direção, pontuamos a afinidade das representações que circulam nos apelos publicitários com uma ideia de individualidade própria de um capitalismo neoliberal, de um "liberalismo individualista", como cosmovisão (Guareschi, 2009). Pensando nos termos de Rolnik, em tais redistribuições de valores, que indicam, entre outras coisas, uma incidência do princípio identitário sobre os processos de subjetivação, numa lógica de apropriação e desapropriação constante, "devires à flor da pele", característica das construções fugazes e necessariamente efêmeras do consumo, temos uma "interioridade" a ser capturada pelos "olhos do visível" - "buraco negro, efeito do corpo vibrátil amortecido de uma subjetividade que ficou reduzida ao ego" (Rolnik, 2011, p. 44) ${ }^{2}$. Trata-se de movimentos do desejo. Desejo que, em sua potência criadora, poderia agir no sentido de desterritorializar a padronização subjetiva produzida por essas construções, mas que justamente, sob incitação, funciona alimentando a reprodução dessas formas, que é o que produz, conforme a autora, a mais-valia de poder para tal reprodução. Para ela, "esse modo de produção da subjetividade dissocia o poder do corpo, faz do corpo uma aptidão, uma capacidade que procura aumentar, invertendo a energia, a potência que poderia resultar disso, e tornando-a uma relação de sujeição estrita", ou seja, é "força ativa tendendo a converter-se em força reativa de conservação" (Rolnik, 2011, p. 107). O desejo sobra como um sorriso, de ambos os lados (o eu e o "outro"), uma expectativa; energia incitada, pelos olhos do visível, a converter a(s) forma(s) em uma imagem projetada, realidade ou ilusão; espetáculos insondáveis que cartografam caminhos abertos de felicidade. E é o desejo que joga com uma frustração: confusão que ameaça revelar a face vulgar da alegria insuflada dos anúncios de revista. 


\section{Antropologia e a arquitetura das emoções}

Ciclos viciados de desejo, que compõe e recompõe necessidades, são uma grande marca da sociedade de consumo atual. Deleuze (2010, p. 332) diz que "a verdadeira história é a história do desejo" e assinala que "um capitalista ou um tecnocrata atuais não desejam da mesma maneira que um mercador de escravos ou que um mercador do antigo império chinês". Portanto, é no limiar, no ponto de encontro entre a economia libidinal e o campo social que se caracterizam e desenvolvem os regimes de consumo e os modos de ser.

Contudo, a racionalidade desta maquinaria da produção atual faz crer que as projeções do desejo, tal como se verificam na sociedade moderna, seriam inerentes ao humano (tido como transcendental). Neste sentido, por exemplo, sociedades primitivas só não manifestariam este afã de usos e sobreposições por serem pré-industriais. Daí porque Campbell (2001) caracteriza, antes de qualquer coisa, como uma arraigada etnocentricidade a tomada do nosso comportamento de consumo como "normal" ou "racional". Segundo o autor, a história (e etnografias) demonstra o contrário do que as primeiras teorias que tratam do comportamento do consumidor levavam a crer: este modelo incessantemente mutável de consumo, esta vertigem do desejo, não só é impensável em (certas) sociedades movidas pela tradição, como é imoral. Nessas sociedades, se a natureza (com a extensão de tudo que pode representar numa cultura) provê todas as necessidades (que se orientam conforme a cultura, a tradição) em quantidade finita e nos limites do suficiente, "os esforços de qualquer indivíduo para 'melhorar' a sua condição, se batendo por novas necessidades, são não apenas vistos como se ameaçassem o conjunto da sociedade, mas como sendo fundamentalmente imorais" (Campbell, 2001, p. 61). Ao colocar seus fundamentos fora de si mesmas, as sociedades primitivas tornam-se natureza (Viveiros de Castro, 2011). Portanto, no tocante às necessidades compartilhadas, nessa cosmologia social, a produção não pode ser apropriada em desequilíbrio, por uma fração da sociedade em detrimento de outra, estabelecendo desigualdades.

Tais sociedades "selvagens" parecem não fazer mais sentido quando interpretadas a partir de nossas referências culturais, uma gama de sentidos tecidos e naturalizados. Condena-se, então, a adolescência evolutiva das referidas sociedades, como se estivessem no início (atraso) de um processo social que culminaria em uma sociedade organizada a partir de valores próximos dos nossos. Universaliza-se, assim, o postulado da semelhança dos primitivos conosco (mais do que nós com eles), e, por serem assim tão parecidos, aspirariam a ser um dia como nós, isto é, "viver felizes sob o signo da santíssima trindade do Homem Moderno: o Estado, o Mercado e a Razão, que são o Pai, o Filho e o Espírito Santo da teologia capitalista" (Viveiros de Castro, 2011, p. 318).

Partindo do pensamento de Clastres (2011) e Viveiros de Castro (2011), pode-se dizer que esta diferença imensa e instável entre o Eu e o Outro não impede, mas antes incita a percepção de elementos de alteridade no coração de nossas caracterizações de identidade e regimes de outra ordem moral na economia dos desejos e necessidades. Debord (1997), em sua abordagem crítica da dinâmica da mercadoria abundante na sociedade moderna (do espetáculo), propõe que a mercadoria "aí está como a ruptura absoluta do desenvolvimento orgânico das necessidades sociais. Sua acumulação automática libera um artificial ilimitado, diante do qual o desejo vivo fica desarmado" (p. 45), a acumulação desse artificial, independente, segundo o ponto de vista do autor, provoca por toda parte certa falsificação da vida social.

Interessa-nos aqui discutir aspectos da relação da experiência emocional com a cultura. $\mathrm{O}$ modo como a cultura local representa a manifestação de algumas emoções diz muito sobre suas relações sociais e seus contornos ideológicos. Se isso não habilita a desessencialização das emoções, certamente permite repensar considerações de alguns paradigmas psicológicos na sua abordagem. A incitação ao prazer, ou a maneira como se cristalizam reações diante de fenômenos "externos" da vida social, muda de cultura para cultura, e evidenciam-se mudanças significativas no passar da história.

Tomando a leitura foucaultiana, entendemos que a atividade simbólica em torno das emoções aparece como um lugar privilegiado de produção do sujeito no contemporâneo - a rigor, poderíamos dizer que em qualquer momento histórico. Porém, a partir da Modernidade, as emoções, ao mesmo tempo que são construídas como processo interpretativo (social), também prometem acesso a um tipo de verdade interior do sujeito, já que são concebidas como forças psicológicas dos indivíduos (apoiadas no senso de singularidade). Assim, atualmente as emoções são abordadas e convocadas em discursos diversos, mas nos toca destacar o discurso publicitário. Esse coloca em cena, por um lado, uma verdade sobre elas, seja ao (buscar, prometer) decifrá-las ou canalizá-las, em sensações, por exemplo, decorrentes da relação com os produtos, da composição com eles; por outro lado, as emoções e sensações, expressadas e obtidas através 
do consumo - e que se substancializam no corpo -, prometem desvelar verdades sobre nós mesmos.

Considerando a estratégia de focalizar o discurso social na abordagem antropológica das emoções (indicada por Abu-Lughod \& Lutz, 1990), pensamos, com Foucault (2010b), na potência desse enfoque para a análise social, na medida em que o filósofo ressalta que os discursos são práticas que sistematicamente formam os objetos de que tratam. São, então, produções a partir das quais se pode analisar cultura ou ideologia como práticas sociais, atadas a relações de poder. Abu-Lughod e Lutz (1990) argumentam que devemos perguntar não somente qual sentido cultural das emoções e como a configuração emocional pode estar relacionada à vida social, mas também como o discurso emocional está implicado no jogo de poder e na operação das mudanças históricas dos sistemas de hierarquia social. O foco no discurso permite pensar na formação de ambos por temas e valores culturais, abre espaço para refletir sobre como ele serve enquanto operador no controverso campo da atividade social, como afeta o campo social, e como se presta enquanto idioma para a comunicação não somente de sentimentos, mas também sobre diversos aspectos de conflito social, figuras de gênero, ou naturalização e estabelecimento de normalidades. Juntamente com as autoras, podemos aferir que, se as emoções são um fenômeno social, os discursos são uma via crucial para a compreensão de como elas se constituem.

O manejo simbólico do que está posto nos discursos $-\mathrm{e}$, ressaltamos aqui, especificamente, o discurso publicitário mais uma vez - produz muito da expectativa quanto a um consumo qualquer, enquanto pese sua face hedonista, a busca do prazer, "pois prazer é, efetivamente, um julgamento feito por quem o experimenta" (Campbell, 2001, p. 92). O prazer que se busca no consumo está, então, na mediação entre a realidade objetiva e a expectativa que se encontra do lado do desejo, do devaneio. Daí porque tudo é tão efêmero, a fugacidade do que está no campo de uma prática de construção imaginativa, que Campbell (2001) identifica como característica essencial do hedonismo moderno, dura o tempo necessário, com uma frustração, que está na distância entre o real e a ilusão. Um produto conhecido pode prometer reaver um prazer limitado de uma experiência vivida, mas é o desconhecido de um novo produto vendido que se envolve com o colorido e esfumaçado de uma projeção imaginada.

O discernimento essencial que se exige é a compreensão de que os indivíduos não procuram tanta satisfação dos produtos quanto prazer das experiências auto-ilusivas que se constroem com suas significações associadas. A atividade fundamental do consumo, portanto, não é a verdadeira seleção, a compra ou uso dos produtos, mas a procura do prazer imaginativo a que a imagem do produto se empresta, sendo o consumo verdadeiro, em grande parte, um resultante desse hedonismo "mentalístico". Encarada dessa maneira, a ênfase tanto na novidade quanto na insaciabilidade se torna compreensível. (Campbell, 2001, p. 130)

As imagens relacionadas aos produtos, reais e ilusórias, lembrando aspectos do espetáculo descrito por Debord (1997), normalmente são prestigiosas, envolvidas em fantasias, quando do lado do espetáculo, mas tornam-se, por ventura, vulgares quando consumidas. E então os produtos de consumo, despidos das significações associadas, do imaginário que participa das enunciações publicitárias, quando finalmente consumidos, muitas vezes revelam a pobreza na sua finalidade de produção, como um mistério revelado.

\section{Considerações finais}

Com base na perspectiva foucaultiana, entendemos que concerne à psicologia social colocar em questão o que somos no presente - e que tal intento só pode ser buscado com alguma consistência se assumimos a complexidade de nossa condição. Em função disso, acreditamos que uma abordagem da psicologia social que se propõe a problematizar os modos de subjetivação atuais se compõe mais potente a partir de cruzamentos interdisciplinares.

Então, neste artigo, buscamos evidenciar algumas questões em torno da relação corpo/ discurso/subjetividade tramando um diálogo entre pensadores oriundos de diferentes campos, partindo do lugar ocupado pelo corpo enquanto convocado pelo consumo, via discurso publicitário. Esperamos, com isto, ter mostrado a relevância de pensar a subjetividade a partir da dinâmica imanente do consumo, que hoje ocupa uma centralidade inegável - mas não indiscutível. Procuramos, articulando contribuições de diversos autores e autoras, potencializar a reflexão acerca dos processos de subjetivação contemporâneos - no que incidem sobre nossa sensibilidade, no que participam das composições culturais - para pensar o quanto a profusão de incitamentos publicitários canaliza "destinos" possíveis dentro de uma hierarquia de posições, lugares e papéis pré-concebidos. Neste sentido, nosso horizonte foi expandir a perspectiva por onde pensar, hoje, os corpos que se codificam, em caracterizações necessariamente provisórias, articulados e adaptados ao empreendimento dos traços significantes colocados à venda, para problematizar lógicas que operam em tais processos. 
A título de finalização, mas também de provocaçãoeabertura, cabepontuarquecompreendemos que os modelos a serem experimentados pelos sujeitos são sempre composições provisórias, cambiantes. Por isso, a partir da observação de Debord (1997, p. 47), de que "o que o espetáculo oferece de perpétuo é fundado na mudança", é pertinente considerar, quiçá "subvertendo" tal concepção que parece apontar mais capturas do que possibilidades, que o vir a ser de cada corpo não se estabiliza a partir de certos (quaisquer) registros de maneira definitiva, sempre havendo espaço para invenção e resistência no que diz respeito à processualidade da produção dos sujeitos.

\section{Notas}

Os valores "se colocam na interface entre nossa consciência e a realidade social ... são forças sociais presentes na sociedade, nos códigos, nos escritos e, ao mesmo tempo, na mente e nos corações das pessoas. Eles nos penetram, nos fazem, nos produzem" (Guareschi, 2009, p. 30).

2 “O 'corpo vibrátil' é a potência que tem nosso corpo de vibrar a música do mundo, composição de afetos que toca em nós ao vivo. Nossa consistência subjetiva é feita dessa composição sensível, criando-se e recriando-se impulsionada pelos pedaços de mundo que nos afetam. O corpo vibrátil, portanto, é aquilo que em nós é o dentro e o fora ao mesmo tempo: dentro nada mais é que uma combinação fugaz do fora.” (Rolnik, 2001, p. 317)

\section{Referências}

Abu-Lughod, L. \& Lutz, C. (1990). Language and the politics of emotion: studies in emotion and social interaction. Cambridge: Cambridge University Press.

Bauman, Z. (2009). Vida líquida (C. A. Medeiros, Trad.). Rio de Janeiro: Zahar.

Bruno, F. (1994). Diet'ética: a saúde na mídia. Revista Eco-Pós, 1(5), 69-82.

Campbell, C. (2001). A ética romântica e o espírito do consumismo moderno (M. Gama, Trad.). Rio de janeiro: Rocco. (Original publicado em 1989)

Calvino, I. (2008). Seis propostas para o próximo milênio (I. Barroso, Trad.). São Paulo: Companhia das Letras. (Original publicado em 1990)

Clastres, P. (2011). Arqueologia da violência. (P. Neves, Trad.) São Paulo: Cosac Naify. (Original publicado em 1980)

Debord, Guy. (1997). A sociedade do espetáculo: comentários sobre a sociedade do espetáculo (E. S. Abreu, Trad.). Rio de Janeiro: Contraponto.

Deleuze G. (2005). Foucault (C. Martins, Trad.). São Paulo: Brasiliense.

Deleuze, G. (2010). A ilha deserta (L. B. L. Orlandi, Trad.). São Paulo: Iluminuras.

Foucault, M. (1996). A ordem do discurso (L. F. A. Sampaio, Trad.). São Paulo: Loyola. (Original publicado em 1971)

Foucault, M. (2002). Vigiar e punir (R. Ramalhete, Trad.). Petrópolis, RJ: Vozes. (Original publicado em 1975)
Foucault, M. (2004). A hermenêutica do sujeito (M. A. Fonseca $\&$ S. T. Muchail, Trads.). São Paulo: Martin Fontes.

Foucault, M. (2010a). A história da sexualidade I: a vontade de saber (M. T. C. Alburquerque \& J. A. G. Albuquerque, Trads.). São Paulo: Graal. (Original publicado em 1988)

Foucault, M. (2010b). A microfísica do poder (R. Machado, Trad.). Rio de Janeiro: Graal. (Original publicado em 1979)

Geertz, C. (1989). A interpretação das culturas. Rio de Janeiro: LTC. Giddens, A. (2002). Modernidade e identidade (P. Dentzien, Trad.). Rio de Janeiro: Zahar.

Guareschi, P. (2009). Psicologia social crítica: como prática e libertação. Porto Alegre: Edipucrs.

Lucas, L. \& Hoff, T. (2006). Da ortopedia ao controle do corpo: o discurso da saúde na publicidade. Comunicação, mídia e consumo, 6(3), 81-103.

Ortega, F. (2001). Michel Foucault: os sentidos da subjetividade. In B. Bezerra \& C. Plastino (Orgs.), Corpo, afeto, linguagem: a questão do sentido hoje (pp. 157-172). Rio de Janeiro: Rios Ambiciosos.

Rolnik, S. (2001). Molda-se uma alma contemporânea: o vaziopleno de Lygia Clark. In B. Bezerra \& C. Plastino (Orgs.), Corpo, afeto, linguagem: a questão do sentido hoje (pp. 315349). Rio de Janeiro: Rios Ambiciosos.

Rolnik, S. (2011). Cartografia sentimental: transformações contemporâneas do desejo. Porto Alegre: Sulina.

Silva, R. N. (2005). A invenção da psicologia social. Petrópolis, RJ: Vozes.

Silveira, F \& Furlan, R. (2003). Corpo e alma em Foucault: postulados para uma metodologia da psicologia. Psicologia USP, 14(3), 171-194.

Sodré, M. (2006). Antropológica do espelho: uma teoria da comunicação linear e em rede. Petrópolis, RJ: Vozes.

Viveiros de Castro, E. (2011). O intempestivo, ainda. In P. Clastres (Org.), Arqueologia da violência (pp. 395-361). São Paulo: Cosac Naify.

Thompson, J. (2008). A mídia e a modernidade: uma teoria social da mídia (W. O. Brandão, Trad.). Petrópolis, RJ: Vozes. (Original publicado em 1995)

Tonin, J. (2007). A imagem em Guy Debord. In C. Gutfriend \& J. M. Silva (Orgs.), Guy Debord: antes e depois do espetáculo (pp. 43-60). Porto Alegre: Edipucrs.

\section{Agência de fomento}

\section{CAPES - bolsa DS.}

Submissão em: 07/12/2012

Aceite em: 27/03/2013

Mário Pereira Borba é mestre em Psicologia Social e Institucional pela Universidade Federal do Rio Grande do Sul (2014). Bacharel em Comunicação Social - Relações Públicas pela Universidade Federal do Rio Grande do Sul (2009). Endereço para correspondência: Rua Ramiro Barcelos, 2600, Floresta, Porto Alegre/RS, Brasil. CEP 90035-003. E-mail: borba.mp@gmail.com

Inês Hennigen é docente do Programa de Pós-Graduação em Psicologia Social e Institucional da Universidade Federal do Rio Grande do Sul. E-mail: ineshennigen@gmail.com 